\title{
Soft Tissue Surrogates Papers
}

\author{
Arnab Chanda
}

\begin{abstract}
Introduction

The following are the references.

$[1][2][3][4][5][6][7][8][9][10][11][12][13][14][15][16][17][18][19][20][21][22][23][24][25][$

$26][27][28][29][30][31][32][33][34][35][36][37][38][39][40][41][42][43][44]$.
\end{abstract}

\section{Materials and Methods}

\section{Results and Discussion}

\section{References}

[1] A. Chanda, V. Unnikrishnan, S. Roy, and H. E. Richter, "Computational Modeling of the Female Pelvic Support Structures and Organs to Understand the Mechanism of Pelvic Organ Prolapse: A Review," Applied Mechanics Reviews. 2015, doi: 10.1115/1.4030967.

[2] A. Chanda, C. Callaway, C. Clifton, and V. Unnikrishnan, "Biofidelic human brain tissue surrogates," Mech. Adv. Mater. Struct., 2018, doi:

10.1080/15376494.2016.1143749.

[3] A. Chanda and V. Unnikrishnan, "CUSTOMIZED INSOLES FOR DIABETIC AND PRESSURE ULCERS,” US 10,172,413 B2, 2019.

[4] A. Chanda and H. Ghoneim, "Pumping potential of a two-layer left-ventricle-like flexible-matrix-composite structure," Compos. Struct., 2015, doi: 10.1016/j.compstruct.2014.11.069.

[5] A. Chanda, R. Graeter, and V. Unnikrishnan, "Effect of blasts on subject-specific computational models of skin and bone sections at various locations on the human body," AIMS Mater. Sci., 2015, doi: 10.3934/matersci.2015.4.425.

[6] A. Chanda, V. Unnikrishnan, H. E. Richter, and M. E. Lockhart, “A biofidelic computational model of the female pelvic system to understand effect of bladder fill and progressive vaginal tissue stiffening due to prolapse on anterior vaginal wall," Int. j. numer. method. biomed. eng., 2016, doi: 10.1002/cnm.2767.

[7] A. Chanda and V. Unnikrishnan, “A REALISTIC 3D COMPUTATIONAL MODEL of the CLOSURE of SKIN WOUND with INTERRUPTED SUTURES," J. Mech. Med. Biol., 2017, doi: 10.1142/S0219519417500257.

[8] A. Chanda, V. Unnikrishnan, Z. Flynn, and K. Lackey, "Experimental study on tissue phantoms to understand the effect of injury and suturing on human skin mechanical properties," Proc. Inst. Mech. Eng. Part H J. Eng. Med., 2017, doi: 
10.1177/0954411916679438.

[9] S. Gupta, G. S. Raghuwanshi, and A. Chanda, "Effect of weather on COVID-19 spread in the US: A prediction model for India in 2020," Sci. Total Environ., 2020, doi: 10.1016/j.scitotenv.2020.138860.

[10] A. Chanda and V. Unnikrishnan, "Human Tissue Simulants for Study of Traumatic Brain Injury (TBI).," Am. Soc. Compos. Thirty-First Tech. Conf., 2016.

[11] A. Chanda and C. Callaway, "Tissue anisotropy modeling using soft composite materials," Appl. Bionics Biomech., 2018, doi: 10.1155/2018/4838157.

[12] A. Chanda, V. Unnikrishnan, and Z. Flynn, "Biofidelic Skin Simulant," US10049601B2, 2018.

[13] A. Chanda, I. Meyer, H. E. Richter, M. E. Lockhart, F. R. D. Moraes, and V. Unnikrishnan, "Vaginal changes due to varying degrees of rectocele prolapse: A computational study," J. Biomech. Eng., 2017, doi: 10.1115/1.4037222.

[14] A. Chanda, V. Unnikrishnan, and Z. Flynn, "Biofidelic Vaginal Tissue Surrogate," 62/263,942, 2015.

[15] A. Chanda, T. Ruchti, and V. Unnikrishnan, "Computational Modeling of Wound Suture: A Review," IEEE Reviews in Biomedical Engineering. 2018, doi: 10.1109/RBME.2018.2804219.

[16] A. Chanda, Z. Flynn, and V. Unnikrishnan, "BIOMECHANICAL CHARACTERIZATION of NORMAL and PROLAPSED VAGINAL TISSUE SURROGATES," J. Mech. Med. Biol., 2018, doi: 10.1142/S0219519417501007.

[17] A. Chanda and V. Unnikrishnan, "Effect of bladder and rectal loads on the vaginal canal and levator ani in varying pelvic floor conditions," Mech. Adv. Mater. Struct., 2018, doi: 10.1080/15376494.2017.1331629.

[18] A. Chanda, V. Unnikrishnan, H. E. Richter, and M. E. Lockhart, "Computational Modeling of Anterior and Posterior Pelvic Organ Prolapse (POP)," no. February 2017, 2016, doi: 10.1115/imece2016-67949.

[19] H. Ghoneim and A. Chanda, "Pumping potential of left-ventrical-like flexible matrix composite structure," ICCM Int. Conf. Compos. Mater., vol. 2013-July, no. July 2013, pp. 7457-7464, 2013.

[20] A. Chanda, V. Unnikrishnan, and K. Lackey, "Biofidelic conductive synthetic skin composites,” 2017, doi: 10.12783/asc2017/15197.

[21] R. F. Kushner, "Bioelectrical impedance analysis: A review of principles and applications," Journal of the American College of Nutrition. 1992.

[22] A. Chanda and K. Curry, "Patient-specific biofidelic human coronary artery surrogates," J. Mech. Med. Biol., 2018, doi: 10.1142/S0219519418500495.

[23] A. Chanda, "BIOFIDELIC SOFT COMPOSITES - EXPERIMENTAL AND COMPUTATIONAL MODELING," University of Alabama, 2017. 
[24] A. Chanda, "Biomechanical Modeling of Human Skin Tissue Surrogates," Biomimetics, 2018, doi: 10.3390/biomimetics3030018.

[25] A. Chanda, T. G. Jones, and K. E. Beschorner, "Generalizability of Footwear Traction Performance across Flooring and Contaminant Conditions," IISE Trans. Occup. Ergon. Hum. Factors, 2018, doi: 10.1080/24725838.2018.1517702.

[26] A. Chanda and V. Unnikrishnan, "Novel insole design for diabetic foot ulcer management," Proc. Inst. Mech. Eng. Part H J. Eng. Med., 2018, doi: 10.1177/0954411918808330.

[27] A. Chanda and R. Graeter, "Human Skin-Like Composite Materials for Blast Induced Injury Mitigation,” J. Compos. Sci., 2018, doi: 10.3390/jcs2030044.

[28] A. Chanda, "Review of Recent Advances in Vaginal Mesh Tissue Interaction," Res. Dev. Mater. Sci., vol. 5, no. 1, pp. 3-5, 2018, doi: 10.31031/rdms.2018.05.000601.

[29] A. Chanda and V. Unnikrishnan, "Subject-Specific Computational Study of Blast Induced Traumatic Injuries," 2015.

[30] V. H. Sundaram, S. L. Hemler, A. Chanda, J. M. Haight, M. S. Redfern, and K. E. Beschorner, "Worn region size of shoe outsole impacts human slips: Testing a mechanistic model,” J. Biomech., 2020, doi: 10.1016/j.jbiomech.2020.109797.

[31] A. Chanda, A. Reuter, and K. E. Beschorner, "Vinyl Composite Tile Surrogate for Mechanical Slip Testing," IISE Trans. Occup. Ergon. Hum. Factors, 2019, doi: 10.1080/24725838.2019.1637381.

[32] A. Chanda and V. Unnikrishnan, "Anisotropic Soft Composite Based Hyperelastic Model," 2018, [Online]. Available: https://osf.io/zdumf/.

[33] A. Chanda, T. Ruchti, and W. Upchurch, "Biomechanical Modeling of Prosthetic Mesh and Human Tissue Surrogate Interaction," Biomimetics, 2018, doi: 10.3390/biomimetics3030027.

[34] A. Chanda, "Customized Human Skin Simulants," pp. 1-11.

[35] K. E. Beschorner et al., "An observational ergonomic tool for assessing the worn condition of slip-resistant shoes," Appl. Ergon., 2020, doi: 10.1016/j.apergo.2020.103140.

[36] A. Chanda, S. Chatterjee, and V. Gupta, "Soft composite based hyperelastic model for anisotropic tissue characterization," J. Compos. Mater., 2020, [Online]. Available: https://journals.sagepub.com/doi/abs/10.1177/0021998320935560.

[37] A. Chanda, V. Unnikrishnan, K. Lackey, and J. Robbins, "Biofidelic conductive skin simulant," US2019/0057624 A1, 2019.

[38] A. Chanda, V. Unnikrishnan, K. Lackey, and J. Robbins, "Biofidelic conductive soft tissue surrogates," Int. J. Polym. Mater. Polym. Biomater., 2020, doi: 10.1080/00914037.2018.1552856.

[39] A. Chanda and S. McClain, "Mechanical Modeling of Healthy and Diseased Calcaneal Fat Pad Surrogates," Biomimetics, 2019, doi: 10.3390/biomimetics4010001. 
[40] A. Chanda and W. Upchurch, "Biomechanical Modeling of Wounded Skin," J. Compos. Sci., 2018, doi: 10.3390/jcs2040069.

[41] A. Chanda and V. Unnikrishnan, "Human Skin-Like Biofidelic Sutures," 2015.

[42] A. Chanda and V. Unnikrishnan, "Numerical Modeling of Skin Wound Closure with Interrupted Sutures," 2015.

[43] A. Chanda and V. Unnikrishnan, "Interrupted Suture Force Estimation for Skin Wound Closure: A Computational Approach," 2015.

[44] A. Chanda and V. Unnikrishnan, "Computational Modeling of the Mechanics of Progression of Anterior Vaginal Prolapse (AVP)," 2015. 